Infrastructure Asset Management Volume 3 Issue 3

The case for internalising externalities in a sustainable rail asset base

Langdon, Gillott, Rodrigues and Parry
Infrastructure Asset Management, 2016, 3(3), 97-105

http://dx.doi.org/10.1680/jinam.14.00026

Paper 1400026

Received 23/06/2014; accepted 03/08/2016

Published online 24/08/2016

Keywords: knowledge management/social impact/sustainability

Published with permission by the ICE under the CC-BY license

(http://creativecommons.org/licenses/by/3.0/) ited

\title{
The case for internalising externalities in a sustainable rail asset base
}

Mark Langdon BA, DipArch

Network Rail, London, UK; Faculty of Engineering, University

of Nottingham, Nottingham, UK (corresponding author:

mark.langdon@nottingham.ac.uk)

Mark Gillott BEng, MSc, PhD

Faculty of Engineering, University of Nottingham, Nottingham, UK
Lucelia Rodrigues BArch, DipArch, MSc, PhD

Faculty of Engineering, University of Nottingham, Nottingham, UK

Tony Parry BSC, PhD, MCIHT

Faculty of Engineering, University of Nottingham, Nottingham, UK

Although the concept of sustainability and sustainable development has tended to be mostly associated with the management of natural resources and the consequent environmental impact, the most accepted definition draws together its social, economic and environmental dimensions. The rail industry, as provider of a low carbon transport system, is well placed to have a significant role to play in promoting an environmental, economic and social balance that can be sustained and afforded for the foreseeable future. This paper suggests that a more comprehensive perspective on the scope of a sustainable intervention in rail infrastructure assets is needed, arguing that the necessary whole life evaluation process should include an additional positive externality: the uplift in knowledge, skill and expertise that comes about as a result of participation in projects and programmes. The inclusion of this benefit would provide a more accurate representation of value to support investment decision-making and strengthen the case for a broader funding base. The demonstration of the correlation between participation in projects and programmes and the consequent uplift in skill, knowledge and expertise could be used to shift the emphasis in rail project planning.

\section{Introduction}

The UN report produced by the World Commission on Environment and Development (WCED, 1987) outlines the need to maintain a social, economic and environmental balance in all development activities. This is also reflected in the International Organization for Standardization's (ISO) 'enduring and balanced approach to economic activity, environmental responsibility and social progress' (BSI, 2010: clause 2.23, note 1). While the term sustainability has tended to take on an environmental association, through works such as Rachel Carson's Silent Spring (Carson, 1962) or James Lovelock's Gaia (Lovelock, 1982), the tributaries of thought that have contributed to this evolution have been numerous and varied. Indeed, it can be argued that it was from the discipline of economics that the most powerful catalyst for this tripartite perspective on human development was prompted with the publication of Schumacher's classic Small Is Beautiful (Schumacher, 1973), which drew together the social, economic and environmental dimensions of human activity from an 'economic' perspective.

By pointing out the ways in which industrial consumption patterns were undermining natural resources by mistaking 'capital' for 'income', Schumacher (1973) made a powerful economic case for environmental protection and conservation. $\mathrm{He}$ also outlined how the current economic theory, in its quest for 'efficiencies' at the expense of human dignity, undermined the multidimensional value of work as a lifelong process of self- improvement. Nearly 30 years later, another economist, Nicholas Stern, was to lend further support from an economic perspective (Stern, 2006). By describing and quantifying, albeit imperfectly, the 'economic cost' of environmental inertia, he made explicit the way in which economic thinking could be brought to bear as a catalyst for environmental change. Stern also added that the critical nature of these issues needed to become an essential prerequisite of economic as well as environmental thinking (Stern, 2006). An effective sustainable development strategy therefore would establish the necessary preconditions for a benign and effective pattern of commercial transactions that could enable an integrated set of interconnections between environmental health, economic growth, genuine productivity and individual selffulfilment. These insights offer an important perspective from which to gain a greater understanding of the nature of work, the way it is undertaken and the resulting effect on skills, expertise and knowledge.

Thus, while sustainable development has tended to focus on and be associated with the appropriate use of natural resources and the consequent environmental impact, it can be argued that it is through the appropriate use of human resource potential that people are most able to realise the greatest value from the entire resource or asset base through astutely targeted interventions. Therefore, it would be through this modified perspective of the true nature and potential evolution of the asset base that people would gain a greater understanding of the nature of the 
interventions that are required to optimise the direction of that evolution in a genuinely sustainable way.

Any notion of 'sustainability' that goes beyond a straightforward continuation or 'sustaining' of 'business as usual' inevitably begs a number of questions about the way in which people will be able to 'continue' the current patterns of economic activity and consumption within a vulnerable environment and that whatever the possible solutions are, they must be socially, environmentally and economically affordable. It can be argued that the rail industry in general, as provider of a low-carbon transport system and an infrastructure provider who serves as guardian of and 'conscience for' rail's infrastructural assets, has a significant role to play in promoting an environmental, economic and social balance that can be sustained and comprehensively 'afforded' for the foreseeable future.

In this paper the authors introduce the idea that a particular externality, currently not considered in the calculations of the 'whole life cost' (WLC) of a rail infrastructure project, should be more effectively described and quantified so its supply side benefit can be taken into account. The authors address different domains in order to thread together the multidisciplinary strands that were considered to be implicated directly in the notion of a 'sustainable intervention'. In doing so, they sought to offer a more comprehensive perspective on an engineering intervention, which extends beyond the technical or technological into areas that more roundly describe the link between the 'engineer' and 'society'. The work explores how these often untracked and unreported supply side benefits can be brought to bear on a more comprehensive understanding of value.

The work outlined here considers the notion of a sustainable engineering intervention in the context of a range of disciplines, domains and concepts that are associated with it. These include the underlying nature of the asset base, WLC and 'value' and their associated 'externalities' and specifically the influence of a particular externality: 'skill, knowledge and expertise' in a system-based multidisciplinary infrastructural system.

This work goes on to consider the significance of including this particular externality in any comprehensive evaluation of potential benefits that need to be taken into consideration when deciding on an appropriate rail investment strategy that ensures that societal requirements are aligned to technical possibilities and economic reality.

The authors argue that the way in which this expertise, skill, knowledge and systemic thinking is managed, directed and targeted will determine the sustainability and ultimate 'affordability' of an infrastructural system that sets out to serve economic, social and environmental needs. This resultant shift of emphasis could be supported by management mechanisms that would place a greater emphasis on expertise evolution as a project output.

\section{Sustainability in the European and national rail contexts}

The opportunity for transport in general and rail in particular to accommodate such an evolution sustainably has been implicit in a range of documents and reports at European, national, regional and local levels, including the European Commission's White Paper on Transport: Roadmap to a Single European Transport Area (European Commission, 2011). The white paper sets out the basis on which European transport policy needs to be directed and sees this as a significant catalyst for socioeconomic improvements across the European region.

This includes the opportunity to address the "quality of work in all transport modes, with respect to, notably, training, certification, working conditions and career development, with a view to creating quality jobs, developing the necessary skills and strengthening the competitiveness of EU transport operators' (European Commission, 2011: p. 21).

Thus, apart from improved transport links and agglomeration benefits for passengers, businesses and freight users, 'sustainable development' can serve as a catalyst for a range of associated benefits in a number of ways. These include business for local supply chains and regeneration that provides new infrastructure for area development and through the job market by creating jobs with a comprehensive range of skill requirements.

Implicit in such a complementary relationship is the opportunity to achieve a more comprehensive demonstration of 'technical' or 'technological' solutions including the expertise needed to realise them including the overall socioeconomic benefit that could be achieved as a consequence of doing so.

While the white paper tends to refer to the prerequisite skill requirements, there is also an opportunity to apply the consequent skills, expertise and knowledge uplift that follows from participation in projects and programmes. And just as it should be possible to internalise transaction costs, it should be possible to internalise these transaction benefits once they have been demonstrated and as far as possible quantified.

This suggests an opportunity to broaden the scope of the economic benefits that the paper advocates by incorporating human resource potential into the 'system': a 'system beyond the system'?

This wider societal focus described in the white paper has also been reflected within national boundaries by national infrastructure providers, moving on from previous models used to justify investment almost totally in terms of user benefit (travel time saved, service frequency, capacity increases etc.).

Published 10 years ago, at the same time as the Stern Review, the Eddington report (Eddington, 2006) broadened the perspective on the relationship between transport and economic success. A year 
later, there followed the Department for Transport's discussion paper Towards a Sustainable Transport System: Supporting Economic Growth in a Low Carbon World (Department for Transport, 2007), which sought to address the Stern and Eddington reports and to prompt a debate as to how they could be translated into policy.

This approach was taken to a further logical step in 2010 when Network Rail produced a discussion paper which addressed the question of rail investment and the need to shift the focus from the benefit for the user to the benefit for the wider economy, adopting an approach which 'prioritises the maximisation of economic growth’ (Network Rail, 2010).

The paper proposed a new appraisal model that would run in parallel with the traditional transport appraisal model with its 'wider economic benefits bolt on'. Thus, instead of asking the question posed in Her Majesty's Treasury's (HM Treasury, 2013) The Green Book: Appraisal and Evaluation in Central Government, 'How do we best spend the tax proceeds of economic growth to increase total welfare?', it suggested that people should instead be asking the question, 'How do we best generate the private sector economic growth that will generate tax proceeds?' (Network Rail, 2010).

This distinction is significant in the context of infrastructure provision, because it moves from the position where investment decisions achieve their public service justification through the 'external' social contribution or 'bolt-on' benefit to a position where they are being incorporated as an active driver for investment decision-making, thereby integrating all associated costs and benefits into the core transaction or, putting this in another way, towards the 'internalisation of externalities'.

Indeed this difference between benefit/cost ratio as a minimum threshold and the greater targeted gains from projects that are envisaged here also challenges the scope of the 'total welfare' that the Green Book seeks to increase and how the latter approach would complement the former. It also raises questions about the relationship of this total welfare to the WLC model that is applied and how they in turn could relate to the 'whole system' that is implicit in a system engineering approach to asset management.

This type of broader more comprehensive interrelationship with rail was further emphasised in 2011 in the George Bradshaw Address when Rick Haythornthwaite, Network Rail's chairman, described the place of the railways in the UK and the opportunity for it to act as a catalyst for a significant culture shift (Haythornthwaite, 2011). The address was unusually wide ranging and drew together a surprising number of social, economic and environmental strands.

Haythornthwaite said, 'There is growing unease amongst many people that we have a society that is fragmented, polarised and even plain disengaged. There is growing sense of the UK as a country that's meandering industrially and hooked on carbon'
(Haythornthwaite, 2011: p. 1). Further, 'If we think back to how the railways of the industrial revolution rewired economic and social behaviour in the 19th century we gain insight into how the infrastructure that we design and build today has the power to reprogram the way we live our lives and move our goods in the post carbon post-industrial era' (Haythornthwaite, 2011: p. 2).

This notion of a 'reprogramming' and 'rewiring' of the way people live their lives increases in resonance as more and more social, environmental and economic interconnections, each with different degrees of emphasis, become apparent within a sustainable systems context (Figure 1).

Implicit in this rewiring process is the consolidation of the accumulated knowledge, skill and expertise that would be necessary to achieve it. The research developed by the authors seeks to look more closely at the nature of this consolidation and to understand the extent to which it can be achieved through railinitiated investment projects and programmes at a national, regional and local level.

\section{The nature of the rail asset base}

The alignment between this rewired 'knowledge/skill/expertise infrastructure' and the configuration of the physical asset base would depend to a significant extent on the perspective from which they are viewed. Should the emphasis should be on the 'elements' that perform functions as they are currently understood or more broadly about what we might describe as the 'service' that needs to be delivered? Which factors determine the relative importance and relative criticality of that service in the broader economic, social and environmental context?

The generally recognised subdivision of asset types in the rail industry takes place along traditional lines: track, buildings, drainage, earthworks, electrical power, level crossings, off-track, signalling, structures and telecoms. While these subdivisions are necessary to describe and understand the specific infrastructural elements, it is becoming increasingly recognised that a more comprehensive grasp of the whole system, which they form a part of, offers a greater opportunity to focus asset interventions where they will have maximum impact.

The assets therefore become increasingly integrated into the system they form a part of as the system itself evolves and flexes. Characteristics that currently define the assets within their existing context are transformed as innovative approaches to the development of systems and subsystems begin to challenge the extent and integrity of the elemental boundaries.

Implicit in this reconfiguration or realignment is its integration into the knowledge base. A systemic rewiring that extends and interconnects the range of operational, commercial and academic disciplines that sit at various points along the quantitativequalitative spectrum. That is, the knowledge infrastructure needed to devise, design, maintain and develop not only the physical 


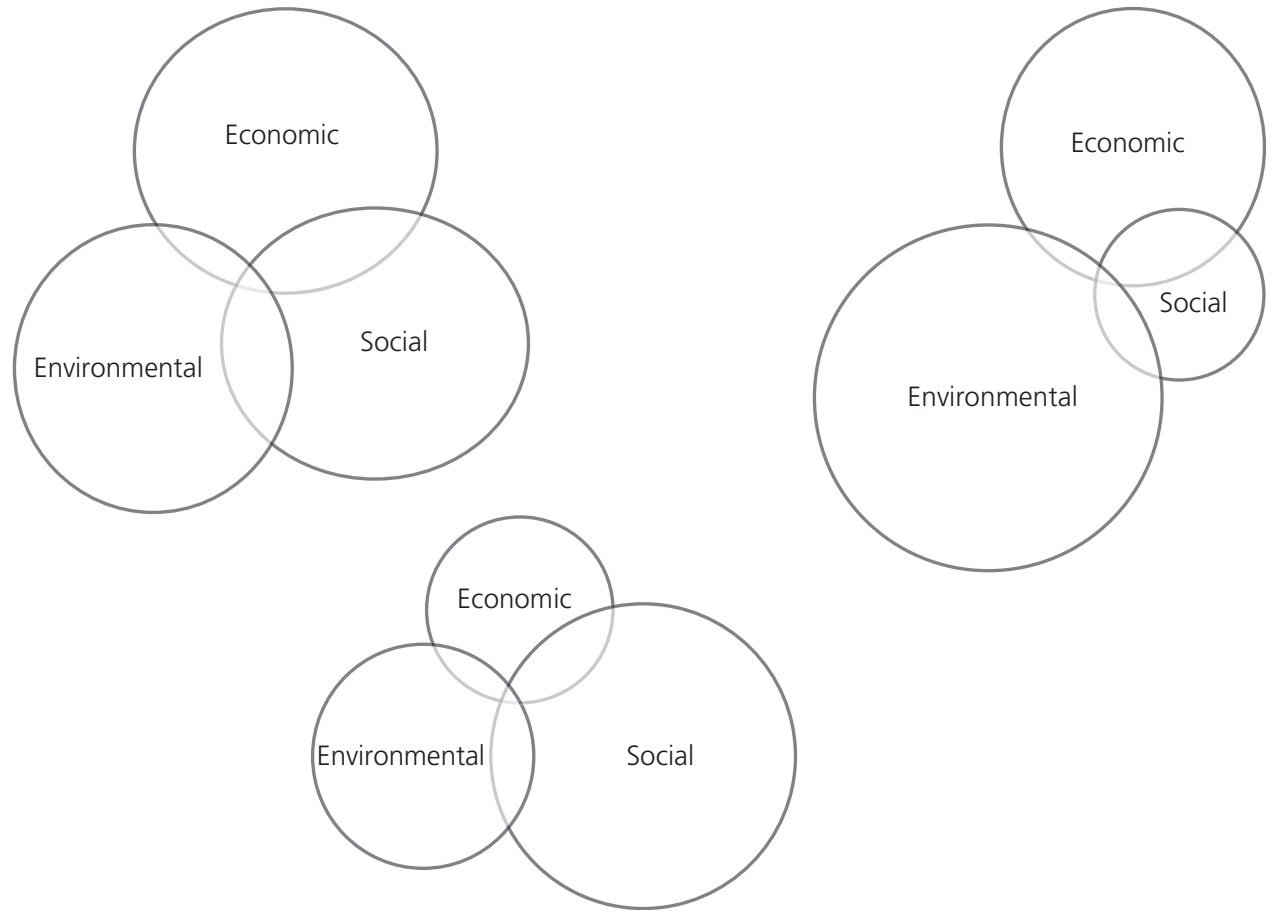

Figure 1. Potential shifts in emphasis and focus of sustainability components within a dynamic systems context

asset base but also the intellectual asset base on which it is built. This work is arguing that any interventions intended to enhance the former are directed and managed in such a way as to ensure the enhancement of the latter.

In parallel with this, the funding allocation for infrastructure investment would take more account of the more comprehensive, holistic, 'whole life' evaluation of potential benefits, the quantification of which often remains elusive. The Network Rail 'Quadrant' or 'Tier' Benefits model provides some support here by formalising this allocation of benefit along the quantitative-qualitative spectrum, often reflecting fine-tuned judgements that need to be taken into account in the broader context of an infrastructure provider's responsibility and remit, a context that would inevitably broaden and deepen as the rewiring process, described earlier, both clarifies existing and establishes new interconnections. Investment decisions would therefore draw on an increasingly broader and deeper multidisciplinary context in order to be sufficiently comprehensive and effective.

Indeed, it can be argued that a more multidimensional, systembased perspective would provide the appropriate context for the accommodation of the externality referred to earlier: the positive change in the skills, knowledge and expertise of the workforce that comes about as a consequence of working on projects and programmes. As these benefits became demonstrably quantifiable, not only would they substantiate the financial integrity of the investment calculation but they would also increase its profile and significance. The next section looks more closely at the nature of economic evaluation that can best accommodate such a reconfigured system.

\section{Whole life costing, life cycle cost analysis, life cycle costing and the significance of externalities}

Key to the effectiveness and integrity of any evaluation process that seeks to determine the affordability of potential renewals and/ or enhancements of the asset base is that they are carried out on a whole life basis. Furthermore, this 'cradle-to-grave' calculation should provide a comprehensive evaluation of all ongoing costs and benefits associated with any proposed changes and justify investment decisions.

Regarded as an imprecise science, WLC evaluations take many forms and are subject to wide interpretations and definitions. Indeed the terms 'whole life cost', 'life cycle costs' and 'life cycle cost analysis' are often used interchangeably. Therefore, as a point of reference, this paper will use ISO 15686-5:2008 (BSI, 2008) in order to define the terms and clarify the relationship between the two. This is illustrated in Figure 2, where the notion of a WLC includes not only life cycle costs, non-construction costs and income but also what are described as externalities. Factors, that while they may be very relevant to a comprehensive assessment of whole life value and affordability are not factored into the financial calculation. 


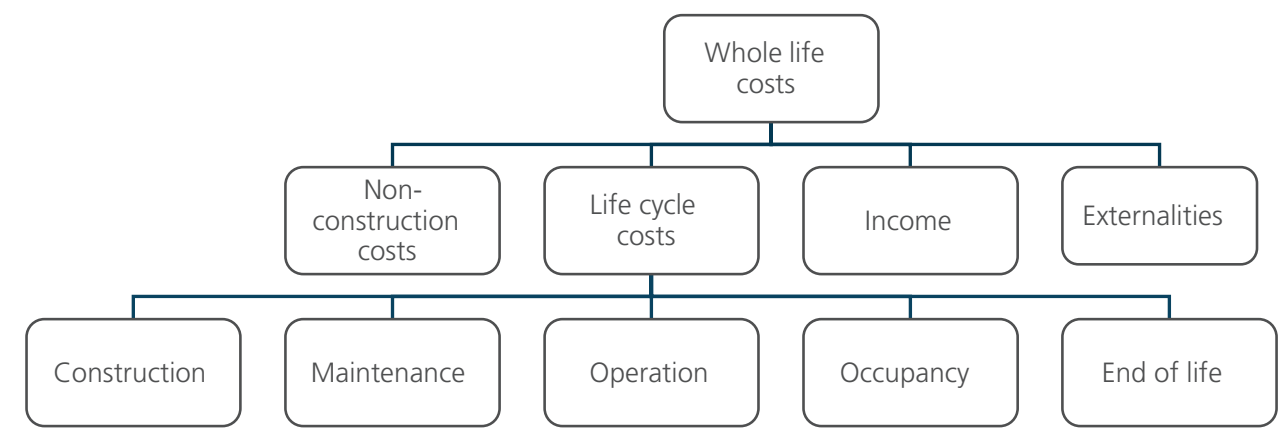

Figure 2. The concept of whole life cost based on ISO 15686-

5:2008 (BSI, 2008)

While acknowledging that whole life value rather than WLC may be a more comprehensive and representative description of the whole life evaluation process, the authors will keep to the latter rather than the former. This is because, firstly, the notion of value is implicit in the ISO definition referring to costs and benefits; secondly, the term 'whole life cost' is more generally recognised in accountancy terminology, whereas the term 'whole life value' is less clearly understood.

At Network Rail the WLC model developed as part of a programme being undertaken with the University of Nottingham addresses the minimum whole life and lifecycle cost concept by way of a modelling hierarchy at three levels. The core model calculates optimum points for asset intervention based on the type and criteria for intervention, moderated by the history, degradation relationships, unit costs and specification. It seeks to optimise the replacement points and intervals by assessing the risk, maintenance and renewal costs of different approaches. The model addresses: life cycle costs, non-construction income and potential income while seeking to establish the optimum method and point of intervention, which once determined is formally sanctioned through the investment process. The model also addresses the life cycle of the assets and takes into account potential income and non-construction costs. It does not currently include such externalities within its scope, although, of course, they may be picked up in social appraisal. The work outlined here addresses the importance of this additional component: the externalised transactions implicit in these calculations, which it argues have the potential to be key components in a 'calculation' of the sustainable value of the broader system under consideration.

The consequential benefit of such a skill/knowledge/expertise enhancement could then be transformed from an incidental to a targeted benefit by a proactive investment strategy that incorporated the uplift in skill/knowledge/expertise into the WLC equation. As the profile and perceived significance of this and other consequential benefits was increased, their potential role in the rewiring process described earlier would be increasingly recognised. Indeed, a considered approach to the evaluation of programme options that looked beyond the delivery of tangible assets may offer opportunities to target directly the evolution of expertise as an integral part of the scope. This shift of emphasis along a deliverables-expertise spectrum is represented in Figure 3.

Indeed, the evolution of this 'knowledge infrastructure' on which the physical asset base depends would be intrinsically linked to any comprehensively 'whole life-costed' investment decision and would have the potential to become one of its principal drivers rather than simply a byproduct of its realisation and delivery. The demonstration of this linkage would also offer the opportunity to further broaden the base for transport funding settlements by giving due recognition to this fundamental asset base that underlies the infrastructure. Thus, when referring to

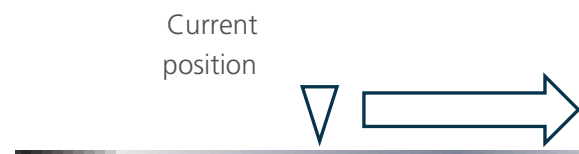

Physical output/ deliverable 
infrastructure services, it should be possible to consider them from a more comprehensive vantage point, to be more conscious of this common ingredient that underlies the contingent elemental subdivisions within the overall infrastructural system and to recognise where the common denominators or 'threads of continuity' lie and what needs to be in place in order to sustain them.

The work outlined here is arguing for a shift in emphasis towards these threads of continuity and a revised perspective from which to view the provision of that sustainable infrastructure. This would give due recognition to the continuum that remains when the different embodiments of the means of conduction and transmission (tracks, cabling, excavations, pipework and networks) have evolved into other forms of infrastructural solution.

\section{The case for considering skills and expertise}

The accretion and evolution of this knowledge/skill/expertise infrastructure, which forms an intrinsic part of the asset infrastructure, by definition has been evolving with the railways as it has with other infrastructural systems. However, a method of explicitly incorporating it into a calculation of asset value has remained elusive.

The elemental asset base at any point in time should by definition be valued according to the latent expertise contained within it and any change, or intervention in the asset base by way of a project or programme would need to factor in the consequent change or modification of this 'expertise infrastructure' when considering different ways of undertaking and delivering projects and programmes.

This suggests the need to gain a greater understanding of what is meant by knowledge, expertise and skill and, further; to understand how to benchmark them during their accumulation both formally and in ways that are not necessarily part of a formalised assessment process and then to describe and provide some form of measurement of the transition through those benchmarked stages.

While studies concerning the nature of knowledge and its accumulation are extensively considered in a broad range of philosophical theories, expertise has, until recently, been less in focus: '.. we have seen much increased interest in expertise as a cultural and social phenomenon, discussed in political debate and as a central concern for organisations' (Farington-Darby and Wilson, 2006: p. 18).

Noting a general decline in opportunities to accumulate and develop expertise in the workplace, accentuated by the reduction of apprenticeships, the Farington-Darby-Wilson paper makes the observation that an expert is often seen as someone who has developed sufficient mastery over their domain that they are able to exercise discretion over which rules to follow and which to waive in the pursuit of their intended outcome. The paper contrasts this approach with more mechanistic interpretation of 'expertise' exemplified by robotics and questions where along this spectrum apparently limited resources should be applied in order to accomplish technically complex tasks within the context of a multidimensional working environment: 'people at work have a vast variety of roles, multiple goals and means and require the integration of social, cognitive and physical skills' (FaringtonDarby and Wilson, 2006: p. 28).

The paper points to two particular models of expertise evaluation that appear to be relevant in this context: firstly, the Dreyfus and Dreyfus skill acquisition model, which describes the stages of expertise accumulation as: novice, competent, proficient, expert and master (Dreyfus and Dreyfus, 1980), and, secondly, the craft skill classification suggested by Hoffman et al. (1995): naivety, novice, initiate, apprentice, journeyman, expert and master.

These are particularly relevant because a great deal of skill/ knowledge/expertise accumulation within the rail infrastructure environment can be achieved by way of a natural on-the-job learning process over an extensive period of time requiring the amalgamation of the practical and the theoretical, the mechanistic and the manual as well as the formal and informal. FaringtonDarby and Wilson (2006: p. 29) argued that 'the move through the stages relies on the individual accumulating situated practical experience, as they move from analytical to intuitive thinking and from seeing a situation in terms of its parts to a situation as a whole'. Thus, the move from parts to whole, elemental to system and segmented analytical to holistic thinking offers an indication of the ways in which the evolution or uplift of expertise would manifest itself as the project participants deepen, broaden and contextualise their knowledge base.

While the work suggested here does not purport to contain anything like the depth of a human factors or ergonomic analysis, it makes reference to the process in order to throw some light on expertise accumulation in an operational context. The way in which on-the-ground exposure to a new range of technical, managerial and operational challenges is assimilated into a preexisting range that predated the project or programme and is taken onto another level.

Establishing the nature of this inter-relationship is challenging in a number of ways: firstly, to demonstrate the causal linkage between the new set of experiences and the change achieved by way of the process of assimilation; secondly, to establish a viable method to measure or describe the 'pre' and 'post' levels of skill/ knowledge/expertise; and, thirdly, to gain greater insights into this process of transition.

A project or programme that incorporates the appropriate disciplines and domains offers some assistance here by providing a spatio-temporal boundary within which to evaluate this change. It also offers the opportunity to consider how a range of technical and 'non-technical' aspects of the project exert varying degrees of influence over the participants and how, as a result of these influences, definable changes can be discerned. 

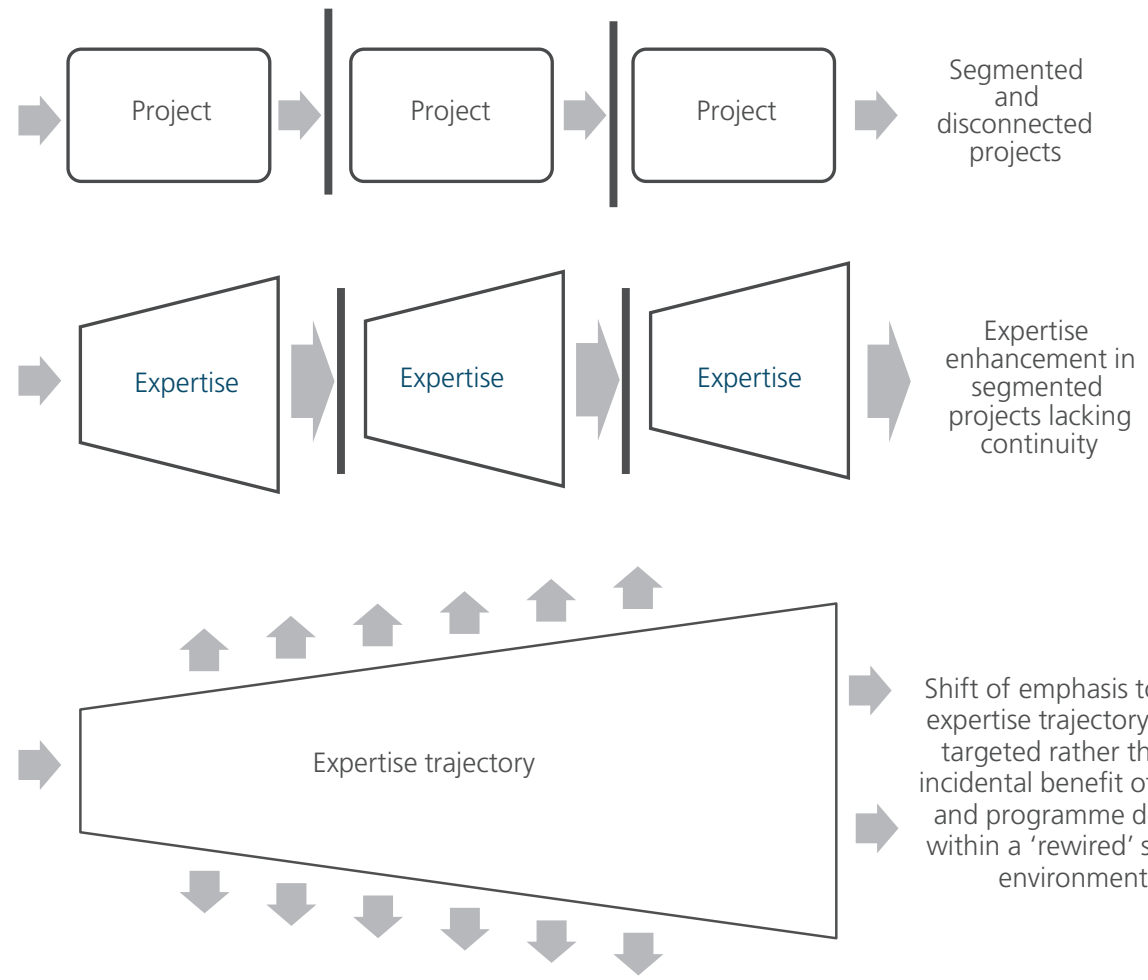

Shift of emphasis towards expertise trajectory as a targeted rather than an incidental benefit of project and programme delivery within a 'rewired' systems environment

Figure 4. Different perspectives from which to view the development of the asset base

Given the extensive domain coverage that rail infrastructure implies, there are clearly many different types and levels of expertise, skill and knowledge enhancement to be considered: from the complex web of different university research programmes at the front end to those required at the delivery end of projects or programmes. It would include some with a great depth and breadth of experience to those who may never have experienced a working environment before.

This paper is drawing attention to an opportunity to shift the emphasis away from the deliverables of projects and programmes towards the evolution and incubation of the skill/knowledge/ expertise stream that is a necessary condition for those components to be delivered. Figure 4 represents the common disconnection between projects and programmes and also the associated discontinuity of knowledge, skill and expertise and how that could be mitigated by placing much greater emphasis on maintaining the continuing evolution of the 'skill streams' or 'expertise streams' required to produce the tangible assets or project deliverables.

Such an expertise trajectory would be significantly influenced by the nature of the participation in projects and programmes, and further research is currently focusing on the nature of this expertise trajectory at the delivery end of projects and programmes in order to test this assertion.

\section{Discussion}

Sustainability or sustainable development manifests itself in many forms and guises. Nevertheless, it is comprehensively represented by a balanced integration of the social, economic and environmental factors that need to be included, either implicitly or explicitly, and with varying degrees of emphasis in the evaluation of options in any business decision.

Central to such a comprehensive evaluation of possible options is that they are considered to be affordable within the context of a whole life calculation. A necessary condition for this 'whole life affordability' is a comprehensive understanding of the value they represent, an evaluation process that must incorporate the relevant externalities into a comprehensive WLC calculation. The authors argue that a critical externality in this calculation is the recognition and evaluation of the common component that threads its way through the asset base: the skill, knowledge and expertise of those that have brought about its current state of realisation.

The way in which the evolution of this expertise, skill, knowledge and systematic thinking is captured, coordinated and managed, within the context of a project or programme environment, will determine the sustainability of an infrastructural system that sets out to serve economic, social and environmental needs, thereby demonstrating a real, robust economic value which more than justifies its 'cost'. 


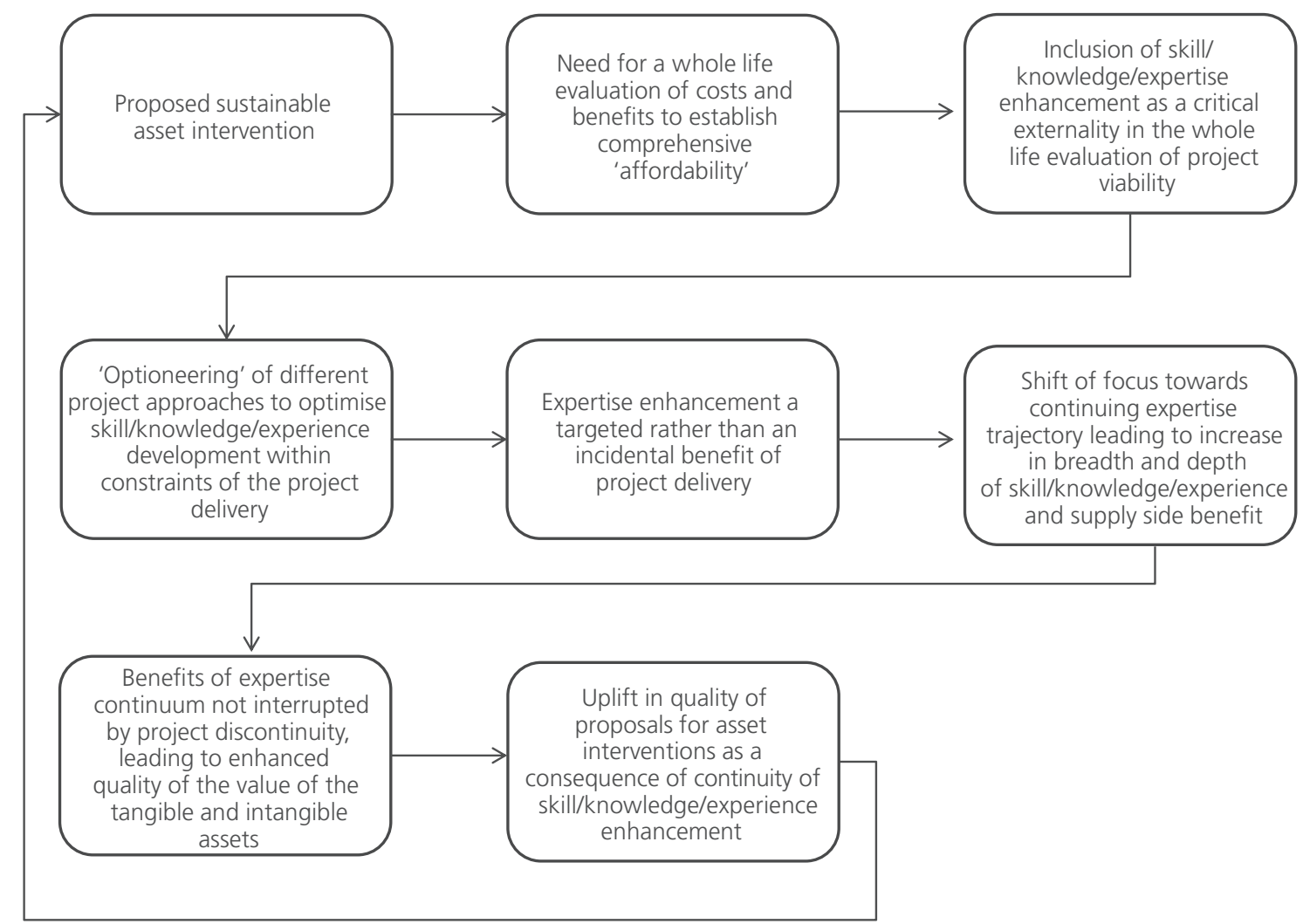

Figure 5. Flow diagram describing the benefits of targeting continuing expertise enhancement

Therefore, the central question raised by the authors about sustainable interventions in rail assets suggests the opportunity for a revised/modified perspective (Figure 5) from which to view this core asset base - that is, by way of the specific externality that should be intrinsic to a meaningful WLC calculation, which is itself a necessary condition for an intervention to be described as sustainable. This in turn requires that as far as possible this externality should be 'internalised' by describing its 'quantifiability' and thereby its integration into the core investment transaction.

This revised perspective is not intending to suggest that the rail investment process does not capture externalities; indeed, the current investment evaluation processes captures socioeconomic externalities both informally and formally by way of project appraisals. It is simply that the process does not recognise the importance of or adequately capture the acquisition of skill/ knowledge and expertise.

Indeed, the technical and broader educational benefits of this expertise enhancement would extend beyond their immediate context to other locations and industries, thereby demonstrating that far from being external to the actual transactions taking place in the process of rail infrastructure investment, this externality is, in fact, very much intrinsic to them.

\section{REFERENCES}

BSI (2008) ISO 15686-5:2008: Buildings and constructed assets service life planning - part 5: life cycle costing. BSI, London, UK.

BSI (2010) ISO 26000:2010: Guidance on social responsibility. BSI, London, UK.

Carson R (1962) Silent Spring. Penguin, London, UK.

Department for Transport (2007) Towards a Sustainable Transport System: Supporting Economic Growth in a Low Carbon World. The Stationery Office, London, UK.

Dreyfus H and Dreyfus S (1980) A 5 Stage Model of the Mental Activities Involved in Directed Skill Acquisition. University of California, Berkeley, CA, USA.

Eddington R (2006) The Eddington Transport Study: The Case for Action. The Stationary Office, London, UK.

European Commission (2011) White Paper on Transport: Roadmap to a Single European Transport Area: towards a Competitive and Resource Efficient Transport System. Publications Office of the EU, Luxembourg, Luxembourg.

Farington-Darby T and Wilson JR (2006) The nature of expertise a review. Applied Ergonomics 37(2006): 17-32, http://dx.doi. org/10.1016/J.APERGO.2005.09.001.

Haythornthwaite R (2011) The George Bradshaw Address: The Place of the Railways in the UK. See http://www. mediacentre.co.uk/resources/george-bradshaw-addressrickhaythornethwaite-06-09-11. 
Infrastructure Asset Management

Volume 3 Issue 3
The case for internalising externalities in

a sustainable rail asset base

Langdon, Gillott, Rodrigues and Parry
HM Treasury (2013) The Green Book: Appraisal and Evaluation in Central Government. HM Treasury, London, UK.

Hoffman R, Shadbolt NR, Burton AM and Klein G (1995)

Eliciting knowledge from experts: a methodological analysis. Journal of Organisational Behaviour and Human Decision Process 62(2): 129-158, http://dx.doi.org/10.1006/obhd.1995. 1039.

Lovelock J (1982) Gaia: A New Look at Life on Earth. Oxford University Press, Oxford, UK.
Network Rail (2010) Prioritising Investment to Support Our Economy. Network Rail, London, UK.

Schumacher EF (1973) Small Is Beautiful. Blond \& Briggs, Abacus, Sphere Books Ltd, London, UK.

Stern N (2006) The Economics of Climate Change - Stern Review. The Stationery Office, London, UK.

WCED (World Commission on Environment and Development) (1987) Report of the World Commission on Environment and Development: Our Common Future. Oxford University Press, Oxford, UK.

\section{HOW CAN YOU CONTRIBUTE?}

To discuss this paper, please submit up to 500 words to the editor at journals@ice.org.uk. Your contribution will be forwarded to the author(s) for a reply and, if considered appropriate by the editorial board, it will be published as a discussion in a future issue of the journal. 